\title{
KNOWLEDGE REGARDING ORAL CANCER AMONG THE RURAL POPULATION IN INDIA
}

\author{
Audrey Madonna D’Cruz'1, Pushparaja Shetty2, Urvashi Ashwin Shetty ${ }^{3}$
}

${ }^{1}$ Reader and PhD Scholar, Department of Public Health Dentistry, AB Shetty Memorial Institute of Dental Sciences, NITTE (Deemed to be University), Mangalore, Karnataka, India.

2Professor and HOD, Department of Oral Pathology and Microbiology, AB Shetty Memorial Institute of Dental Sciences, NITTE (Deemed to be University), Mangalore, Karnataka, India.

${ }^{3}$ Lecturer, Department of Oral Pathology and Microbiology, AB Shetty Memorial Institute of Dental Sciences, NITTE (Deemed to be University), Mangalore, Karnataka, India.

\begin{abstract}
BACKGROUND
ABSTRACT

Oral Cancers (OCs) are the cancers of the oral cavity and oropharynx having high morbidity and mortality rates worldwide. Early detection and treatment are the key to reduce this burden of disease, for which people need to be aware of the causes, risk factors and signs of the disease.

The aim of this study is to assess the knowledge regarding the causes, risk factors, signs and symptoms, treatment of oral cancer among the rural population of Dakshina Kannada district.
\end{abstract}

\section{MATERIALS AND METHODS}

A cross-sectional survey was carried out using a self-administered, pilot tested questionnaire among rural population of Dakshina Kannada. The data obtained was tabulated and analysed.

Statistical tests used: Descriptive statistics (number, percentages) was used. Unpaired t-test was used to compare the mean knowledge scores among males and females.

Setting and Design- A community-based setting. A cross-sectional study design.

\section{RESULTS}

A total of 504 subjects participated in the survey. The mean overall knowledge among men was $3.84 \pm 4.9$ and females was $3.83 \pm$ 5.5. Regarding risk factors, the mean knowledge among men was $0.89 \pm 1.57$ and females was $0.88 \pm 1.9$. The mean knowledge score regarding the symptoms of oral cancer was $1.29 \pm 2.46$. The mean knowledge among men was $0.82 \pm 2.08$ and females was $0.82 \pm 2.03$

\section{CONCLUSION}

The present study concluded that the knowledge regarding oral cancer was very low among the rural population in Dakshina Kannada district.

\section{KEY WORDS}

Rural, Mouth Cancer, Risk Factors, Early Detection.

HOW TO CITE THIS ARTICLE: D'Cruz AM, Shetty P, Shetty UA. Knowledge regarding oral cancer among the rural population in India. J. Evolution Med. Dent. Sci. 2018;7(29):3293-3295, DOI: 10.14260/jemds/2018/741

\section{BACKGROUND}

Oral Cancers (OCs) are the cancers of the oral cavity and oropharynx. Globally, oral cancers constitute about 2-10\% of all cases of cancers in the body and majority of them (about $85-90 \%$ ) are squamous cell carcinoma. ${ }^{1}$ The annual incidence exceeds 300,000 globally and in India almost 80,000 cases are diagnosed annually. ${ }^{2}$ In India, it ranks first in terms of incidence among men and third among women. ${ }^{3}$

Oral cancers may occur de novo or most of the times have a precancerous phase. Early stages of oral cancer have a better prognosis than the advanced stages, but unfortunately

'Financial or Other Competing Interest': None.

Submission 02-06-2018, Peer Review 29-06-2018,

Acceptance 05-07-2018, Published 16-07-2018.

Corresponding Author:

Audrey Madonna D'Cruz,

Reader,

Department of Public Health Dentistry,

AB Shetty Memorial Institute of Dental Sciences,

NITTE (Deemed to be University),

Mangalore, Karnataka, India.

E-mail: audreydcruz@yahoo.co.in

DOI: $10.14260 /$ jemds $/ 2018 / 741$ they are usually detected at advanced stages (stage III and IV) due to which the prognosis may be very poor. The survival rate is very poor. The average of five-year survival rate being $50 \%{ }^{4}$ Although, medical science has advanced with sophisticated surgical and non-surgical treatment available there has been no significant improvement in the 5-year survival rate. Early detection of Oral Potentially Malignant Disorders (OPMDs) and oral cancers is very important in achieving a good prognosis and thus reducing the morbidity and mortality rates. ${ }^{5}$

Use of tobacco (smoke/ smokeless) and alcohol are the predominant risk factors in the epidemiology of oral cancer. Approximately, $75 \%$ of oral cancers are due to the use of tobacco and alcohol. ${ }^{5}$ India is the second largest producer and consumer of tobacco. The use of smokeless tobacco is more common than smoking and is a significant factor for occurrence of oral cancer. ${ }^{6}$ People need to be aware of the risk factors, the signs and symptoms associated with oral cancer. Delays in the diagnosis of oral cancers have been reported to be associated with both health care professionals and patients.7,8 Literature has shown that there is a strong association between lack of awareness understanding of patient regarding oral cancer, due to which there is a delay in 
availing treatment. ${ }^{7}$ The American Cancer Society recommends a comprehensive Oral Cancer examination annually for individuals who are of age 40 years or more and every 3 years for adults less than 40 years of age. ${ }^{9}$

It has been proven that increase in awareness on Oral cancer could help reduce the burden of disease and its related morbidity. Hence, the present study aimed to assess the knowledge regarding the causes, risk factors, signs and symptoms, treatment of oral cancer among the rural population of Dakshina Kannada district.

\section{MATERIALS AND METHODS}

A cross-sectional survey was carried out using a selfadministered, pilot tested questionnaire among rural population of Dakshina Kannada. The study was conducted among the patients attending the camps in Rural Dakshina Kannada district. Convenience sampling method was used in the present study. Patients who were willing to participate in the study and signed the informed consent were included in the study.

The survey tool was a self-administered questionnaire in the local language (Kannada), which consisted of 3 sections. Section 1 was concerning the socio-demographic details of the participants; Section 2 enquired about their present/ past tobacco habits; Section 3 assessed the participant's knowledge on causes, risk factors, signs/ symptoms and treatment regarding oral cancer.

The questionnaire was pretested by conducting a pilot study and test-retest reliability of the questionnaire was assessed using kappa statistics, which was found to be 0.74 (Moderate). Based on the results of the pilot study and on previous literature where the oral cancer knowledge was $16 \%, 10$ the sample size was calculated based on the formula:

Sample size $(\mathrm{N})=\mathrm{Z}_{1-\alpha / 2}{ }^{2} \mathrm{pq} \div \mathrm{d}^{2}$

Where $\mathrm{Z}_{1-\alpha / 2}=1.96$

$\mathrm{p}=$ prevalence $(16 \%)$

$\mathrm{q}=1-\mathrm{p}$

$\mathrm{d}=$ relative precision (estimated at $20 \%$ of $\mathrm{p}$ )

The sample size was estimated to be 504 according to the above-mentioned formula.

Ethical approval to conduct the study was obtained from the Institutional Ethics Committee. The data obtained was tabulated in MS Excel for Windows and analysis was done using the SPSS version 17.0 (SPSS Inc., Chicago). Descriptive analyses (Number and Percentage) were used in the present study. The unpaired t-test was used to compare the mean knowledge scores among males and females.

Correct responses were scored '1.' Incorrect responses and 'Don't know' responses were scored as '0.' The knowledge score was obtained by summing all the correct responses for the individual.

\section{RESULTS}

A total of 504 subjects participated in the survey. Among them, 276 were males. The age of the participants ranged from 18 years to 82 years (Table 1 ).

\begin{tabular}{|c|c|c|c|}
\hline & & Frequency & Percent \\
\hline \multirow{3}{*}{$\begin{array}{c}\text { Age in } \\
\text { Years }\end{array}$} & $<20$ & 24 & 4.8 \\
\cline { 2 - 4 } & $21-30$ & 101 & 20.0 \\
\cline { 2 - 4 } & $31-40$ & 146 & 29.0 \\
\hline
\end{tabular}

\begin{tabular}{|c|c|c|c|}
\hline & $41-50$ & 118 & 23.4 \\
\hline & $51-60$ & 61 & 12.1 \\
\hline & $61-70$ & 40 & 7.9 \\
\hline & $\begin{array}{l}71 \text { and } \\
\text { Above }\end{array}$ & 14 & 2.8 \\
\hline & Total & 504 & 100.0 \\
\hline \multirow{3}{*}{ Gender } & Male & 276 & 54.8 \\
\hline & Female & 228 & 45.2 \\
\hline & Total & 504 & 100.0 \\
\hline
\end{tabular}

The mean knowledge score was $3.85 \pm 0.3$. The mean knowledge among men was $3.84 \pm 4.9$ and females was $3.83 \pm 5.5$, the difference was not statistically significant.

\begin{tabular}{|c|c|c|c|}
\hline & & Mean \pm SD & Significance \\
\hline \multirow{3}{*}{$\begin{array}{c}\text { Total } \\
\text { Knowledge }\end{array}$} & Overall & $3.85 \pm 0.3$ & \\
\hline & Males & $3.84 \pm 4.9$ & \multirow{2}{*}{$\begin{array}{c}\mathrm{t}=0.0216 \\
\mathrm{df}=502 \\
\mathrm{p}>0.05, \text { non- } \\
\text { significant }\end{array}$} \\
\hline & Females & $3.83 \pm 5.5$ & \\
\hline \multirow{3}{*}{$\begin{array}{l}\text { Knowledge } \\
\text { on Risk } \\
\text { Factors }\end{array}$} & Overall & $1.53 \pm 2.07$ & \multirow{3}{*}{$\mathrm{t}=0.06, \mathrm{df}=502}$, \\
\hline & Males & $0.89 \pm 1.57$ & \\
\hline & Females & $0.88 \pm 1.9$ & \\
\hline \multirow{3}{*}{$\begin{array}{l}\text { Knowledge } \\
\text { on } \\
\text { Symptoms }\end{array}$} & Overall & $1.29 \pm 2.46$ & \\
\hline & Males & $0.82 \pm 2.08$ & \multirow[b]{2}{*}{$\begin{array}{c}\mathrm{p}>0.05, \text { non- } \\
\text { significant }\end{array}$} \\
\hline & Females & $0.82 \pm 2.03$ & \\
\hline
\end{tabular}

\section{DISCUSSION}

Of the 504 subjects, only $55.2 \%(n=278)$ have heard of oral cancer. When asked about risk factors for oral cancer, very few (23.8\%) had recognised alcohol as a risk factor. About $37.1 \%$ had identified tobacco as a risk factor and majority of them $57 \%$ did not know that tobacco was a risk factor. Very few participants identified poor fitting dentures (9.1\%), low consumption of fruits and vegetables (9.1\%), eating hot and spicy food regularly (7.1\%). The mean knowledge score regarding the risk factors for oral cancer was $1.53 \pm 2.07$. The mean knowledge among men was $0.89 \pm 1.57$ and females was $0.88 \pm 1.9$, the difference was not statistically significant.

When asked about the signs of oral cancer, only $19.8 \%$ responded correctly that longstanding/ non-healing wound anywhere in the mouth and $17.9 \%$ identified presence of red/ white patch as a sign. About $18.5 \%$ identified burning mouth as a sign for oral cancer. Majority (76\%) are not aware that inability to open mouth is a sign of oral cancer. Most of them were not aware of the signs of oral cancer. About $75.6 \%$ were unaware of difficulty in swallowing as a sign of oral cancer and $75.2 \%$ were not aware of lump or swelling and difficulty in speech as a sign of oral cancer. The mean knowledge score regarding the symptoms of oral cancer was $1.29 \pm 2.46$. The mean knowledge among men was $0.82 \pm 2.08$ and females was $0.82 \pm 2.03$, the difference was not statistically significant.

Only $28.4 \%$ responded correctly that oral cancer does not spread from person to person and $30.2 \%$ were aware that it can be prevented. About $54.8 \%$ did not know whether oral cancer can be treated or not and only $36.3 \%$ agreed that oral cancer causes death.

India contributes up to $7.8 \%$ of the global cancer burden and $8.33 \%$ of global cancer deaths. ${ }^{2}$ Despite various advances 
in technology and treatment modalities, the mortality and morbidity associated with oral cancer is very high. Among the various factors attributed to this increased prevalence, ignorance, tobacco use, lack of awareness of signs and symptoms of oral cancer are noteworthy. The present study was done to assess the knowledge regarding oral cancer among the rural population in Dakshina Kannada district. The results showed that there was a lack of awareness regarding oral cancer among the general population.

Regarding the knowledge of risk factors for oral cancer, the results of the present study were in accordance to the study conducted by Pakfetrat et al ${ }^{10}$ and Cruz et al.11 Oral cancer usually is seen in the fourth to fifth decade of life and tobacco and alcohol are the major risk factors for occurrence. Pakfetrat et al reported that only $15.9 \%$ reported tobacco use as a risk factor and $6.6 \%$ identified alcohol consumption as risk factors for oral cancer. ${ }^{10}$ In contrast, Misirlioglu $\mathrm{M}$ et al reported that majority of participants were aware of the carcinogenic effects of tobacco and alcohol $186.5 \%$ and $63.6 \%$, respectively). ${ }^{11}$ In the present study, about $37.1 \%$ had recognised tobacco and about $23.8 \%$ identified alcohol consumption as risk factor for oral cancer. Other risk factors for oral cancer include increased consumption of hot and spicy food, low consumption of fruits and vegetables, illfitting dentures etc. Very few participants $(>10 \%)$ in the current study were aware of the other risk factors of oral cancer. Cruz et al reported that even the public who were interested in participating in cancer screening programs lacked adequate knowledge on risk factors and importance of early detection of oral cancer. ${ }^{12}$

Regarding the knowledge on clinical signs and symptoms of oral cancer, Misirlioglu $\mathrm{M}$ et al reported that $56.8 \%$ of subjects were unaware of common clinical presentations of oral carcinomas and only $25.2 \%$ identified non-healing lesions as early signs for oral cancer. ${ }^{12}$ About $6.4 \%$ and $7.3 \%$ identified red lesions and white lesions respectively as early signs for oral cancer. In contrast about $19.8 \%$ in the present study reported that longstanding/ non-healing wound anywhere in the mouth and $17.9 \%$ identified presence of red/ white patch as an early sign of oral cancer. Tomar et al reported that $50 \%$ of study participants were aware that red and white lesions could be cancerous lesions. ${ }^{13}$ Pakfetrat et al reported that $90 \%$ of the subjects were unaware of the common clinical presentations of oral cancer. ${ }^{10}$ Just $8.8 \%$ of the participants were aware of the most likely sites of occurrence. Only $6.6 \%$ of the participants were aware of ulcers, whereas the presence of red and white lesions was mentioned by only $0.9 \%$ of the cases and $6.9 \%$ cited exophytic lesions as early signs of oral cancer. West et al reported that 1 in 3 patients in their study identified white patch and 1 in 4 identified red patch as an early sign of oral cancer. ${ }^{14}$

\section{CONCLUSION}

The present study concluded that the knowledge regarding oral cancer is very low among the rural population in
Dakshina Kannada. To reduce the burden of oral cancer, early detection and prompt treatment is the key. However, low knowledge regarding the causes, signs and prevention of oral cancer could be a major barrier for early detection and diagnosis of oral cancer. Concerted efforts should be made by healthcare providers, public health professionals, NonGovernmental Organisations towards increasing awareness among the people, especially the rural population and organising oral cancer screening programs.

\section{REFERENCES}

[1] Mayne S, Morse D, Winn D. Cancers of the oral cavity and pharynx. In: Schottenfeld D, Fraumeni J Jr, eds. Cancer epidemiology and prevention. $3^{\text {rd }}$ edn. New York: Oxford University Press 2006: p. 674-96.

[2] Coelho KR. Challenges of the oral cancer burden in India. J Cancer Epidemiol 2012;2012:701932. http://dx.doi.org/10.1155/2012/701932.

[3] Byakodi R, Byakodi S, Hiremath S, et al. Oral cancer in India: an epidemiologic and clinical review. Journal of Community Health 2012;37(2):316-9.

[4] Gómez I, Warnakulasuriya S, Varela-Centelles PI, et al. Is early diagnosis of oral cancer a feasible objective? Who is to blame for diagnostic delay? Oral Dis 2010;16(4):333-42.

[5] Johnson NW, Warnakulsuriya KA. Epidemiology and aetiology of oral cancer in the United Kingdom. Comm Dent Health 1993;10(Suppl 1):13-29.

[6] Waranakulasuriya KA, Harris CK, Scarrott DM, et al. An alarming lack of public awareness toward oral cancer. Br Dent J 1999;187(6):319-22.

[7] McLeod NM, Saeed NR, Ali EA. Oral cancer: delays in referral and diagnosis persist. $\mathrm{Br}$ Dent J 2005;198(11):681-4.

[8] Donnell A, Jin S, Zavras AI. Delay in the diagnosis of oral cancer. J Stomatol Invest 2008;2:15-26.

[9] Alfano MC, Horowitz AM. Professional and community efforts to prevent morbidity and mortality from oral cancer. J Am Dent Assoc 2001;132 Suppl 1:S24-S9.

[10] Pakfetrat A, Falaki F, Esmaily HO, et al. Oral cancer knowledge among patients referred to Mashhad Dental School, Iran. Arch Iran Med 2010;13(6):543-8.

[11] Misirlioglu M, Nalcaci R, Yardimci SY, et al. Oral cancer knowledge among Turkish dental patients. Clin Cancer Investig J 2013;2(2):149-52.

[12] Cruz GD, Le Geros RZ, Ostroff JS, et al. Oral cancer knowledge, risk factors and characteristics of subjects in a large oral cancer screening program. J Am Dent Assoc 2002;133(8):1064-71.

[13] Tomar SL, Logan HL. Florida adult's oral cancer knowledge and examination experiences. J Public Health Dent 2005;65(4):221-30.

[14] West R, Alkhatib MN, Mcneill A, et al. Awareness of mouth cancer in Great Britain. $\mathrm{Br}$ Dent J 2006;200(3):167-9. 